\title{
Preoperative Endocrine Therapy
}

National Cancer Institute

\section{Source}

National Cancer Institute. Preoperative Endocrine Therapy. NCI Thesaurus. Code C16194.

Short term endocrine therapy, prior to surgery, to "down-stage" primary breast cancer in order to increase the rate of breast-conserving surgery. (from JMCC 7:557-562, 2000 via Medscape) 